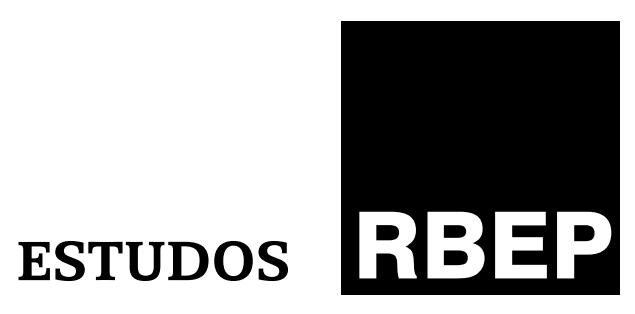

\title{
O ensino superior indígena como política pública: elementos para a construção de um modelo metodológico de avaliação e comparação de experiências locais
}

Luis Roberto de Paula

\section{Resumo}

São duas as principais modalidades de ensino superior ofertadas a estudantes indígenas no Brasil em universidades públicas federais, estaduais e faculdades particulares: a licenciatura intercultural e as vagas suplementares/reserva de vaga. Ambas possuem diversas variáveis infraestruturais, acadêmicas e políticas em comum; muitas outras, entretanto, afastam-nas significativamente. Todo o exercício de descrição e análise presente neste artigo, bem como a proposição preliminar de um modelo comparativo ao final do trabalho têm como eixo metodológico a identificação e descrição dessas variáveis e sua articulação a uma sequência analítica, que organiza a experiência concreta do público-alvo em três etapas processuais e interdependentes, aqui denominadas acesso, permanência e inserção no mercado de trabalho.

Palavras-chave: estudante indígena; licenciatura intercultural; políticas públicas. 


\section{Abstract \\ Indigenous higher education as a public policy: methodological model building for evaluate and compare local experiences}

There are two main modalities of higher education offered to indigenous students in Brazilian Universities, considering both public and private ones: the intercultural teaching degree and the preferred admissions systems (quotas). These two policies have many infra structural, academic and political variables in common, on the other hand, a great number of variables distance them from each other. The exercise of description and analysis presented in this article, as well as the preliminary proposition for a comparative method outlined in the end of this work, has as a methodological guideline the identification and description of the above mentioned variables as well as their articulation to the analytical sequence that organises the concrete experience of the target public in three interdependent processual stages: job access, job permanence and job insertion.

Keywords: indigenous student; intercultural teaching degree; public policy.

\section{Introdução}

São duas as principais modalidades de ensino superior ofertadas a estudantes indígenas no Brasil em universidades públicas federais e estaduais e faculdades particulares: a licenciatura intercultural e as vagas suplementares/reserva de vaga. A primeira tem como objetivo prioritário formar professores indígenas (ou, em muitos casos, dar continuidade à formação) para atuar em escolas situadas em terras indígenas. A segunda modalidade direciona candidatos indígenas para a formação em um conjunto de outros cursos regulares oferecidos por diversas universidades públicas (federais e estaduais) e particulares. Seu objetivo é formar profissionais indígenas para atuar prioritariamente em suas comunidades de origem em áreas como odontologia, medicina, enfermagem, agronomia, biologia etc. ${ }^{1}$

Reproduzo aqui a distinção precisa apresentada por Amaral (2010, p. 118, nota 100) sobre as modalidades de inserção: "Ressalta-se a distinção entre cotas e vagas especiais ou suplementares considerando que as cotas se caracterizam pela definição de um número determinado de vagas para um grupo social específico no cômputo das vagas gerais disputadas no concurso vestibular. As vagas especiais ou suplementares se caracterizam por exceder o número de vagas gerais, não afetando a concorrência dos demais candidatos." O que falta dizer aqui é que, pelo fato de as vagas

\footnotetext{
${ }^{1}$ A presença de alunos indígenas na pós-graduação (que também pode ser encontrada nas duas modalidades citadas), apesar de ainda tímida no Brasil, é outra frente a ser investigada e pode, como será visto, ser diagnosticada a partir das variáveis propostas neste artigo.
} 
suplementares serem, justamente, "suplementares", elas não possuem uma fonte de recursos garantida dentro do orçamento da universidade. Isso traz sérias implicações para a etapa de permanência dos alunos indígenas na universidade. Assunto para bons diagnósticos comparativos.

Segundo estimativa apresentada pelo pesquisador Rodrigo Cajueiro (2007) sobre ações afirmativas no ensino superior para povos indígenas, existiam por volta de 5.000 estudantes universitários indígenas, entre formados e formandos, em 2007. Já era um número razoável àquela época, pois "os mais de 230 povos indígenas somam, segundo o Censo IBGE 2010, 896.917 pessoas. Destes, 324.834 vivem em cidades e 572.083 em áreas rurais, o que corresponde aproximadamente a 0,47\% da população total do país" (População..., [s.d.]). As duas modalidades de ensino superior indígena podiam ser encontradas, então, em 30 universidades estaduais e 21 federais, dado que revela que há um aprendizado institucional acumulado em mais de 50 instituições de ensino superior.

As duas modalidades de ensino superior, a licenciatura indígena e as vagas suplementares, possuem muitas variáveis infraestruturais, acadêmicas e políticas em comum; muitas outras, entretanto, afastamnas significativamente. Todo o exercício de descrição interpretativa que se segue, bem como a tentativa de proposição de um modelo de análise que venha a reboque desse exercício, tem como eixo metodológico a identificação e apresentação dessas variáveis infraestruturais, acadêmicas e políticas que se encontram entrelaçadas na arquitetura de formulação e implementação de ambas as modalidades de ensino superior indígena em curso no País.

Desta maneira, o leitor se deparará a seguir com um esforço analítico ordenado por meio de uma sequência de três etapas processuais que serão denominadas acesso, permanência e inserção no mercado de trabalho. Essa divisão analítica, associada aos subconjuntos de variáveis selecionadas para levar adiante o exercício proposto, organizará o exercício de contraste, que será feito no decorrer deste artigo, entre as duas modalidades de ensino superior em tela.

As três etapas se encontram, na prática social, conectadas tanto entre si quanto à trajetória escolar dos estudantes indígenas, desde seus primeiros momentos de contato com o letramento até sua inserção no mercado de trabalho. O tipo de educação escolar indígena oferecido - ou imposto - a cada uma das mais de 230 etnias presentes em território nacional será um fator de destaque em todo esse trajeto. Maior ou menor ênfase no bilinguismo ou no monolinguismo (seja ele em língua materna indígena ou em língua portuguesa) deve ser um fator decisivo em um diagnóstico que busque avaliar, por exemplo, a permanência ou a evasão dos estudantes indígenas no ensino superior em ambas as modalidades. Outro momento fundamental, no qual a biografia escolar do candidato indígena se faz decisiva, ocorre diante do vestibular indígena.

Cabe dizer que, certamente, o leitor deve estar se perguntando quais seriam então as grandes diferenças dessa trajetória indígena, quando comparadas às dos não índios: biografia escolar, vestibular. A resposta 
é que estamos lidando com um público-alvo composto por mais de 230 etnias, que fala 180 línguas distintas, que possui cosmologias e histórias de contato e, portanto, processos culturais e de escolarização complexos e diversificados. Há povos que só falam o português como primeira língua; outros que só falam, praticamente, a língua do grupo. Imagine-se, leitor, diante da tarefa de organizar uma prova de vestibular para um grupo de candidatos tão heterogêneo. Que tipo de currículo, calendário, professor, infraestrutura, material didático a universidade deve oferecer àqueles alunos indígenas que tenham realizado esse rito de passagem para a etapa de permanência?

A terceira etapa seria a inserção no mercado formal de trabalho, precedida por um segundo ritual de passagem, a formatura. Variáveis como um diagnóstico qualitativo e quantitativo da evasão escolar indígena e dos destinos profissionais daqueles que se formaram são alguns dos componentes de um modelo de avaliação e comparação.

Quase não existem estudos etnograficamente densos e sistematicamente comparados (e comparáveis) que tenham como objeto essas três etapas de escolarização dos povos indígenas de maneira integrada. A despeito dessa ausência, é possível encontrar uma série de avaliações parciais de experiências locais que nos ajudam a refletir sobre essa temática. $^{2}$

Os objetivos fundamentais deste artigo podem ser anunciados assim: 1) identificar e descrever etnograficamente as etapas que compõem a política pública em foco, observando, na medida do possível, temáticas, atores, interesses, cenários, conflitos, normatizações e ações que a compõem; 2) propor um roteiro de variáveis para que se componha um modelo de análise que permita a construção de parâmetros metodológicos suficientes para contrastar e comparar experiências de inserção no ensino superior, em suas duas modalidades mais conhecidas.

Destacando-se o aspecto etnográfico das argumentações que se seguem, subsidiado por minha experiência como professor e coordenador de habilitação envolvido na Licenciatura Intercultural da Faculdade de Educação da Universidade Federal de Minas Gerais (UFMG), bem como por minha breve passagem pela Coordenação de Acesso e Permanência de Vagas Suplementares para Alunos Indígenas na mesma instituição, passo então a descrever densamente as três etapas aqui referenciadas.

Foram escolhidas três grandes variáveis para descrever interpretativamente a etapa de acesso ao ensino superior indígena: o perfil da educação escolar indígena, tal qual é oferecido aos estudantes indígenas e vivenciado por eles em suas trajetórias individuais, seja nas escolas das comunidades indígenas de que fazem parte ou fora das terras indígenas, comumente, em escolas públicas da periferia das grandes cidades; a condição étnica dos candidatos indígenas e, por conseguinte, em tese, o grau de reconhecimento étnico da comunidade indígena com a qual o candidato se identifica e por ela é identificado; intrinsecamente vinculada à primeira variável, o papel do diálogo entre saberes no processo seletivo, isto é, quais os conteúdos da experiência local nativa

\footnotetext{
${ }^{2}$ Veja, por exemplo, um conjunto de comunicações apresentadas no Simpósio Temático 4 "Saberes tradicionais e formação acadêmica no âmbito da educação superior", promovido em 2010 pela Universidade Católica Dom Bosco (UCDB), no Mato Grosso (http://www.neppi. org/eventos/4sustentabilidade/ simposio4.htm). Ou, ainda, o dossiê da Revista Brasileira de Estudos Pedagógicos ( $\mathrm{n}$. 233, jan./abr. 2012) sobre a questão das ações afirmativas envolvendo negros e índios nas universidades.
} 
e os conteúdos disciplinares do currículo nacional a prova do vestibular específico exige do candidato indígena.

Nas duas modalidades de ensino superior em foco, o evento que marca o auge da etapa de acesso para a vida universitária - o vestibular indígena - encontrará nessas três variáveis os elementos sociopolíticos definidores da aprovação ou reprovação do candidato indígena. As três variáveis, em seu conjunto, terão influência significativa tanto nas duas modalidades como em todas as três etapas do processo de escolarização superior indígena e inserção no mercado de trabalho. São diversos os elementos acadêmicos, políticos e infraestruturais envolvidos na produção de um vestibular indígena, de sorte que sua abordagem seria tarefa para um artigo específico. Porém, gostaria apenas de elencar alguns pontos importantes que dizem respeito aos bastidores da logística necessária para a realização desse evento. O vestibular indígena necessita de uma logística de divulgação/comunicação intensa, organizada pela instituição que abriga a experiência de ensino superior, para alcançar o resultado esperado, ou seja, atrair um número razoável de candidatos indígenas tanto na inscrição como na realização da prova. O público-alvo dessa política se encontra, em muitos casos, em terras indígenas situadas em regiões de difícil acesso às redes de informação. Há candidatos que, uma vez avisados da abertura do edital para o processo seletivo, perdem a possibilidade de inscrição por falta de acesso à internet: muitas instituições, de uma maneira um tanto incompreensível, não permitem que a inscrição seja efetuada por outras vias, por exemplo, preenchimento de formulário de forma manual na aldeia e envio de inscrição via correio.

Mesmo que se supere essa fase, é igualmente complexo proporcionar as condições logísticas para que o candidato possa participar efetivamente do processo seletivo. A maioria das universidades exige que o candidato faça a prova no campus universitário, o que, independentemente da justeza ou não da orientação, elimina muitos potenciais candidatos. Algumas, ao flexibilizarem o local da prova, colocando postos para a sua realização em pontos próximos a algumas terras indígenas, beneficiam alguns grupos em prejuízo de outros. Há um interessante reflexo dessa limitação logística quando contrastamos as duas modalidades de ensino superior indígena, tendo como ilustração a UFMG. Enquanto a modalidade licenciatura indígena atrai uma grande maioria de candidatos indígenas de povos regionais (Minas Gerais, Espírito Santo e Sul da Bahia, principalmente), a modalidade vagas suplementares atrai candidatos indígenas de todo o Brasil. Do ponto de vista da instituição, um fator decisivo, no caso das licenciaturas, é que a proximidade geográfica entre comunidades e universidade facilita o processo intermodular, que, necessariamente, é realizado nas áreas indígenas, ao passo que o ponto de vista do nativo ainda deve ser investigado. Por exemplo, o porquê de os Pataxó do sul da Bahia não estudarem nas universidades (estaduais e federais) de seu Estado, que oferecem licenciatura intercultural e estão geograficamente mais próximas da comunidade, poderia ser explicado por redes de parentesco que ligam a comunidade Pataxó da Bahia à comunidade de Minas que, por 
sua vez, já tinha uma trajetória de inserção no ensino superior indígena da UFMG. Mas isso é somente especulação.

Superadas essas dificuldades, há o processo de homologação das inscrições, que é realizado pelos professores-especialistas da instituição. Essa fase nos recoloca diante da variável condição étnica, temática fundamentalmente relacionada ao campo da política indigenista nacional. O vestibular indígena, como o próprio nome evidencia, é exclusivamente disputado por candidatos que se autoidentificam indígenas e são identificados da mesma forma por sua comunidade de origem. Esse critério é válido para ambas as modalidades de ensino superior indígena. Entretanto, definir quem é índio e quem não é, no Brasil, não tem sido tarefa fácil, e os reflexos repercutem de maneira significativa entre os principais atores envolvidos nessa fase delicada que compõe a etapa de acesso ao ensino superior. Sem tempo e espaço suficientes para dedicar a todos os aspectos que essa temática mereceria, cabe apresentar e comentar ao menos parte deles. Primeiro, diferentemente do que imagina o senso comum, a condição étnica de um indivíduo e da comunidade indígena da qual faz parte não é - segundo a Convenção 169 da Organização Internacional do Trabalho (OIT), devidamente ratificada pelo Estado brasileiro - definida pela manutenção de traços socioculturais atemporais, tais como fenótipos ameríndios, moradia em terra indígena, manutenção da língua e costumes ancestrais e mais uma gama de atributos primitivistas. Ao contrário, a condição étnica é definida na perspectiva antropológica moderna pelo que já foi assinalado anteriormente: os próprios índios definem os elementos que os diferenciam da sociedade global; trata-se, portanto, de um debate e um posicionamento eminentemente político. ${ }^{3}$ Assim, de um modo mais didático, não cabe nem à Fundação Nacional do Índio (Funai), tampouco a um antropólogo, a definição de quem é sujeito ou não de políticas públicas voltadas para povos indígenas, mas sim às próprias coletividades que se autoidentificam como tais. Essa identificação permite assegurar o acesso das coletividades às políticas públicas diferenciadas (nos campos da regularização fundiária, da assistência à saúde, do acesso à educação, etc.). Mas, aqui, surge um aparente paradoxo. No ato de homologação da inscrição de um candidato ao vestibular indígena, o grupo de professores da instituição de ensino avaliará uma série de documentos que permitem identificar, simultaneamente, a condição étnica do indivíduo e da coletividade indígena da qual faz parte. Ora, segundo a concepção da antropologia moderna - que orienta, ou deveria orientar, as políticas públicas atuais -, se cabe aos índios a autoidentificação étnica, qual o sentido de uma junta de professores não índios participar decisivamente desse procedimento de validação da condição étnica alheia? A resposta para isso talvez seja que, se não cabe ao Estado nacional (travestido aqui de junta de professores da instituição) se imiscuir nesse processo diretamente, cabe a ele, pelo menos, produzir mecanismos que assegurem que esse delicado processo político - que associa a valorização de identidades coletivas diferenciadas
${ }^{3}$ Cajueiro (2007, p.9) já tinha deixado a pergunta: "A partir de que parâmetros se tem reconhecido o público-alvo das políticas de tratamento diferenciado no Brasil? Ou seja, como definir quem tem direito a estes direitos?". 
${ }^{4}$ Uma liderança indígena urbana me questionou certa vez sobre a possibilidade da associação indígena urbana da qual ela era diretora ter o direito de emitir "carteiras de identificação indígena" para os "parentes", levando assim, a meu ver, a ferro e fogo a proposição de autonomia étnica. Afirmei que ela deveria por um lado, transformar esta reivindicação num documento e enviar para avaliação legal da universidade e, por outro talvez o passo mais importante -, levar esse tema para debate no movimento indígena nacional.

${ }^{5}$ São muitas as situações de índios urbanos no País - há desde aglomerados de famílias ou mesmo indivíduos que passaram a reconhecer sua condição étnica a partir do momento em que o IBGE colou essa variável no censo nacional (2000) até conjuntos de famílias extensas que migraram para a cidade atrás de melhores condições de vida e ainda mantêm vínculos fortes com a comunidade de origem. ao acesso a direitos básicos de cidadania (um paradoxo de dar calafrios a qualquer iluminista tradicional!) - tenha legitimidade jurídica suficiente para ser respeitado como uma ação de Estado, ou seja, como política pública. Com esse espírito, formulários nos quais o candidato assume sua filiação étnica, somados a outros em que a coletividade da qual faz parte ratifica essa condição, são parte do processo de homologação da inscrição. Temos, assim, consolidado um procedimento técnico-político, que articula: 1) a autoidentificação individual indígena; 2) a ratificação dessa condição individual pela coletividade indígena; 3) a averiguação de uma comissão de professores da instituição promotora do processo seletivo sobre a legitimidade de toda a documentação apresentada, visando evitar ao máximo qualquer possibilidade de fraude. ${ }^{4}$

Infelizmente, todo esse cuidado não basta para evitar polêmicas sobre a legitimidade ou não da condição étnica de candidatos indígenas. Quando a comunidade indígena é reconhecida oficialmente pelo Estado brasileiro, o que significa em termos bastante concretos, fundamentalmente, ter uma terra já demarcada (que no campo indigenista denomina-se pelo jargão "índios aldeados"), o processo de homologação é bastante tranquilo. Entretanto, quando o indivíduo e a coletividade autoidentificada na documentação não encontram reconhecimento mais formalizado pelo Estado nacional, a questão se complica em demasia. É o caso, por exemplo, de coletividades indígenas denominadas emergentes, ou seja, que buscam o reconhecimento étnico, a demarcação de terras, entre outros direitos garantidos por lei. As definições sobre o pertencimento étnico de indivíduos a esses grupos costumam ser um tanto inconsistentes, o que tem implicações diretas sobre quem é e quem não é detentor da filiação grupal. Situação bem mais complicada é a de indivíduos indígenas desaldeados, ou seja, que não mantém mais vínculo algum com suas comunidades indígenas de origem, e estas, por decorrência, em muitos casos, negamlhes o reconhecimento étnico exigido no processo de homologação de inscrições no vestibular indígena. Alguns casos exemplares dessa situação, que poderíamos denominar etnicidade marginalizada, ocorrem com mais frequência entre os denominados índios urbanos. ${ }^{5}$

Uma vez superados os obstáculos relativos ao acesso às informações que divulgam o processo seletivo, à logística de inscrição via internet, ao deferimento da sua condição étnica sem contestações, às possibilidades de arcar com despesas de transporte para a realização da prova, o candidato indígena se defronta com o momento-chave da etapa de acesso ao ensino superior: a realização da prova que vai aferir de maneira inescapável o perfil da educação escolar indígena do candidato. A associação entre o capital cultural e educacional acumulado pelos candidatos em suas trajetórias e o nível de conhecimentos exigidos pela banca de professores que organizam o processo seletivo será fator decisivo neste momento. Normalmente, a aposta do processo seletivo é no diálogo entre saberes. Diferentemente das fases do vestibular indígena descritas até aqui - que interpõem praticamente os mesmos problemas e soluções para todos os candidatos indígenas -, o nível de exigência dos conhecimentos prévios 
para auferir a aprovação do candidato indígena difere sobremaneira quando a modalidade é a licenciatura indígena ou a de vagas suplementares. Isso tem uma explicação bastante lógica: enquanto a modalidade licenciatura indígena permite um processo de ensino-aprendizagem que tem total continuidade com a trajetória dos candidatos que, pelo menos, nos últimos 20 anos estudaram a maior parte da vida em escolas indígenas marcadamente orientadas pelo ensino intercultural, bilíngue e diferenciado, a modalidade vagas suplementares implicará um corte radical nesse processo. Uma vez iniciado o curso na odontologia ou na medicina, por exemplo, o candidato indígena vai ter que se haver com suas dificuldades em relação ao domínio da forma e dos conteúdos exigidos pela universidade tradicional. Importante seria sistematizar quais conteúdos locais e universais são exigidos nas provas de ambos os vestibulares. Aliás, essa verificação poderia e deveria continuar na próxima fase, a da permanência, principalmente pelo diagnóstico contínuo da articulação de ambos os conhecimentos nos cursos de licenciatura intercultural. ${ }^{6}$

Finalizando esse tópico, o domínio do letramento (em termos de forma e conteúdo) é muito mais decisivo para os candidatos indígenas aprovados na modalidade vagas suplementares. Não por acaso, tem sido bastante comum que os aprovados no vestibular nessa modalidade sejam aqueles que tenham um perfil de educação escolar que associa, dentre outros elementos, o estudo fora da aldeia (ou o estudo na aldeia em escola não diferenciada) e o início ou mesmo término de cursos universitários anteriores. Essa afirmação pode gerar imediatamente a seguinte ilação: o ensino nas escolas das aldeias, uma vez que aposta no diferenciado, ou seja, na articulação entre saberes locais e universais, traria dificuldades ao aluno indígena em formação, no que diz respeito ao processo de aquisição mais competente do letramento, tão exigido, anos depois, pelas universidades. Talvez essa hipótese tenha em parte sua validade, a depender de contextos e situações étnicas a serem investigadas. Entretanto, há outro lado desse debate tão válido quanto o anterior: o ensino diferenciado deveria ser estendido também à modalidade de vagas suplementares. ${ }^{7}$ Um projeto de universidade indígena tem se mostrado um caminho interessante de ser trilhado como resposta plausível.

Uma vez superado o ritual de iniciação para ter acesso à vida universitária, as especificidades das duas modalidades de ensino superior indígena aqui em foco - licenciatura indígena e vagas suplementares aparecem, finalmente, de maneira clara, quando os enfim estudantes indígenas iniciam a etapa da permanência.

O estudante indígena da primeira modalidade terá a sua disposição aquilo que o Ministério da Educação (MEC) preconiza para a educação escolar indígena, em seu nível de ensino básico (infantil, fundamental e médio), ${ }^{8}$ ou seja, os atributos de educação específica, diferenciada, intercultural e bilíngue. De que maneira isso se realiza no ensino superior? Em termos de calendário diferenciado, os estudantes indígenas ingressos na licenciatura indígena terão dois módulos regulares anuais, de 4 a 5 semanas cada, intercalados por dois intermódulos realizados nas terras
6 ${ }^{6}$ possível que a presença de
estudantes indígenas nos cursos
de vagas suplementares/reservas
de vagas estimule um ou outro
professor a trazer para o centro
da sua disciplina - por exemplo,
medicina ou direito-o diálogo de
saberes e, quem sabe, estimular
um ou outro aluno não índio a
trabalhar com povos indígenas
no futuro.
7 Como vaticinou o professor
Antonio Carlos de Souza Lima,
do Museu Nacional, tratar-
se-ia de "rever as estruturas
universitárias muito mais
radicalmente. Ao incluir os
indígenas nas universidades,
há que se repensar as carreiras
universitárias, as disciplinas,
abrir novas (e inovadoras)
áreas de pesquisa, selecionar
e repensar os conteúdos
curriculares que têm sido
ministrados e testar o quanto
estruturas, que acabaram se
tornando tão burocratizadas e
centralizadoras, podem suportar
se forem colocadas a serviço de
coletividades vivas, histórica e
culturalmente diferenciadas"
(apud Silva, 2010 ).
8 A Resolução CNE/CEB no 3,
de 10 de novembro de 1999,
fixa diretrizes nacionais
para o funcionamento das
escolas indígenas e dá outras
providências (Brasil. CNE, 1999). 
indígenas. ${ }^{9}$ Os materiais didáticos utilizados durante o curso são, em muitos casos, produzidos pelos próprios alunos indígenas em formação junto com seus professores. Há um cuidado e atenção com as formas de ensino-aprendizagem que cada aluno carrega em sua bagagem, e o corpo de professores não indígenas é, via de regra, especialista no trato com a temática indígena, sendo responsáveis pela formulação, gestão e execução das disciplinas que compõem o currículo diferenciado e sustenta a formação dos estudantes indígenas. Seria interessante investigar, por exemplo, quais são as metodologias de ensino utilizadas pelos professores não índios especialistas diante dos alunos de licenciatura indígena. Alguns optam pelo clássico método construtivista (das experiências pedagógicas e conhecimentos locais para chegar ao global); há outros que apostam na possibilidade da articulação simultânea dos dois conhecimentos, por meio da leitura/interpretação ad hoc, em sala de aula, de textos acadêmicos densos em termos teóricos. É uma temática que merece uma investigação profunda.

O principal elemento político-pedagógico do currículo diferenciado - base da formação do estudante indígena licenciando - é o chamado percurso acadêmico. É com esse instrumento organizativo que o estudante indígena da licenciatura compõe sua trajetória acadêmica, articulando variáveis como disciplinas a serem cursadas, temáticas a serem pesquisadas como trabalho de conclusão de curso, escolha do perfil mais adequado de professor-orientador e de oficinas oferecidas no currículo, que possam atender demandas para a formação específica em alguma área (por exemplo, o domínio de uma nova tecnologia como a internet e outras ferramentas de rede) etc. Apesar dos esforços pioneiros existentes na direção contrária, o percurso acadêmico começa a ser apropriado pelos estudantes indígenas de maneira mais individualizada. Uma pena, pois em boa parte das licenciaturas indígenas existe um conjunto de estudantes que pertence às mesmas etnias e terras indígenas, que poderiam realizar, coletivamente, diagnósticos de questões e temas que interessam às suas respectivas comunidades. Os percursos, já que estão amarrados ao estudo de temas articulados às condições sociais e ambientais da comunidade indígena/terra de origem, poderiam compor um banco de dados com múltiplas temáticas derivadas desse diagnóstico socioambiental da situação vivenciada pelo grupo indígena. Com base nesse banco de dados, cada um poderia trilhar seu percurso de maneira mais individualizada, se assim julgasse mais conveniente. Outro elemento importante que compõe essa discussão é a necessidade premente dos novos alunos acessarem pesquisas já realizadas por turmas indígenas anteriores sobre temáticas por eles escolhidas, no momento da sua formação. É notável, nesse mesmo sentido, a dificuldade existente com relação a um acesso mais organizado a materiais dessa mesma natureza, já produzidos por Organizações não Governamentais (ONGs) indigenistas, ministérios governamentais etc. Novamente, aparece a necessidade de formação de um banco de dados que contenha esse amplo material, que possa ser disponibilizado para 
os alunos tanto nas bibliotecas da universidade como nas situadas em escolas das aldeias.

Se a classificação como diferenciado, intercultural e específico se encaixa como uma luva na modalidade licenciatura indígena de ensino superior - já que (daí a sua lógica) serão esses estudantes, que, após o segundo ritual de passagem, irão se deparar com a condição de protagonistas da educação escolar indígena, em suas terras indígenas -, na modalidade das vagas suplementares, a realidade é exatamente contrária. Os estudantes dos cursos regulares que compõem as vagas suplementares (no caso da UFMG, medicina, odontologia, enfermagem, biologia, ciências sociais e agronomia) terão de "viver a ferro e fogo", seguindo a regra do jogo clássica da universidade, ou seja, sem concessão de qualquer tipo de flexibilização de conteúdos, metodologias, material didático, calendário etc.

O emblemático dessa distinção radical entre as duas modalidades de ensino superior é a questão de como as variáveis tempo/espaço se encontram associadas a elas: enquanto os estudantes da licenciatura indígena terão uma relação bastante esporádica com o campus da universidade - duas ou três vezes por ano -, a ocasionalidade será a marca da relação entre os estudantes das vagas suplementares e suas comunidades de origem, já que passarão a maior parte do tempo de suas vidas universitárias (4, 5 ou 6 anos) na cidade onde se localiza a universidade (para não dizer que, na maior parte do tempo, o aluno indígena estará na universidade: laboratórios, salas de aula, bibliotecas, bandejão). A possibilidade de uma espécie de banzo indígena ocorrer é bastante razoável, e não deve ser um fator a ser descartado nas estatísticas de evasão escolar: "Denize deixou sua comunidade em 2008, distante 600 km de Porto Alegre, e morou durante quatro anos e meio na Casa do Estudante da UFRGS enquanto frequentava as aulas e realizava os estágios do seu curso. Neste período, relata que o principal desafio foi enfrentar a saudade da família." (Primeira..., 2012 - grifos meus).

Se não há dados precisos sobre a quantidade total de estudantes cursando, atualmente, as diversas modalidades de ensino superior indígena, é mais difícil ainda identificar quantos são os formados e, principalmente, quais teriam sido suas trajetórias e destinos profissionais. ${ }^{10}$ Sabemos que boa parte deles tem atuado como professores indígenas em suas escolas, até porque, quando na licenciatura indígena, esses professores/estudantes já ocupavam essa condição.

Em 1999, foi realizado, pelo Instituto Nacional de Estudos e Pesquisas Educacionais (Inep) e pela Secretaria de Educação Fundamental (SEF) do MEC, o primeiro, e até agora único, Censo Escolar Indígena, com o objetivo de coletar informações gerais sobre as escolas, os professores e os estudantes indígenas. Os dados coletados só vieram a público em dezembro de 2001, e, de acordo com esse censo escolar, existem hoje em terras indígenas 1.392 escolas, onde lecionam 3.998 professores, sendo 3.059 índios e 939 não índios, para 93.037 estudantes. (Grupioni, 2003).
10 "O Censo 2010 indicou que $52,9 \%$ dos indígenas não tinham qualquer tipo de rendimento, proporção ainda maior nas áreas rurais $(65,7 \%)$. Porém, vários fatores dificultam a obtenção de informações sobre o rendimento dos trabalhadores indígenas: muitos trabalhos são feitos coletivamente, lazer e trabalho não são facilmente separáveis e a relação com a terra tem enorme significado, sem a noção de propriedade privada". Análise de rendimentos indica relações diferenciadas dos indígenas com o trabalho (IBGE. Censo 2010). 
Um trabalho muito interessante nessa direção é a tese de doutorado de Amaral (2010) que, por ter trazido elementos para compor o enredo das outras duas etapas discutidas anteriormente (acesso e permanência), certamente ajuda-nos a visualizar o que seria a operacionalidade do roteiro de questões levantadas, que poderão vir a compor um modelo de avaliação e comparação entre experiências locais.

Interessa destacar que parte das variáveis que compõem a organização do roteiro dessa terceira etapa foi extraída do capítulo 4, especialmente de um item denominado "inserção e o envolvimento dos estudantes indígenas universitários no circuito de trabalho indígena intra ou interaldeias durante e (ou) após a conclusão do curso" (Amaral, 2010, p. 461). Há outras variáveis que eu e outros colegas temos identificado no decorrer da implantação de ambas as modalidades de ensino superior indígena.

Muitos indigenistas, antropólogos ou outros profissionais que convivem com povos indígenas identificam, facilmente, ex-alunos do ensino superior indígena que se transformaram em lideranças de associações indígenas; assessores de seu próprio povo em projetos captados com o "mercado de projetos" (Bruce, [s.d.]); funcionários de órgãos governamentais (federais, estaduais e municipais); ou, até mesmo, profissionais que trabalham no terceiro setor regional, no qual estão localizadas suas terras (comércio, garimpo, fazendas). Um bom exemplo desse necessário diagnóstico aparece em Amaral (2010, p. 461, nota 353):

As entrevistadas apresentam suas expectativas de contratação pela Funasa ou pelas Prefeituras Municipais, por meio de concurso público ou contrato temporário pelas organizações não governamentais terceirizadas que gerenciam os programas federais de saúde indígena, bem como por meio de indicação dos caciques, considerando a inexistência de médicos e demais profissionais indígenas de saúde, assim como devido às redefinições acerca da organização da política de saúde indígena no Brasil.

Só um esforço compartilhado por uma rede de colaboradores indígenas e não indígenas distribuídos pelos quatro cantos do País poderia dar conta de tal empresa. Como estímulo à construção de uma estratégia dessa natureza, é possível encontrar algumas notícias dispersas em fontes mais ou menos confiáveis da imprensa virtual que tratam do tema da inserção no mercado de trabalho de estudantes indígenas graduados. Selecionei um trecho de uma dessas notícias, publicada no site de uma entidade sindical - União Geral dos Trabalhadores do Mato Grosso do Sul (UGT-MS) -, que aborda, durante uma mesa redonda com depoimentos indígenas, em abril deste ano, na primeira plenária estadual realizada pela UGT-MS, protestos de indígenas contra o preconceito sofrido no mercado de trabalho. Vejamos:

Mesmo com formação acadêmica e competência para atuar, muitos não conseguem espaço para desenvolver suas atividades profissionais por preconceito da sociedade. "De toda a nossa comunidade quem sofre mais com a discriminação é a mulher. Para elas, a situação é mais 
complicada, porque existe muita exploração de mão de obra escrava", disse a coordenadora das mulheres da Arpipan (Articulação dos Povos Indígenas do Pantanal). Os índios revelaram ainda que as usinas de cana de açúcar são as que mais praticam trabalho escravo e as que mais abusam do trabalho indígena. Segundo o presidente da UGT-MS, Fábio Bezerra, há denúncias de que nessas usinas os patrões oferecem energéticos e estimulantes para as pessoas produzirem mais que o limite tolerado pelo corpo. "Não podemos aceitar que situações como estas continuem acontecendo, por isso é importante encontros como este, para ficarmos a par dos problemas vividos pelos trabalhadores", explica. (Sarzi, 2011, grifos meus).

Pouca importância dada à formação acadêmica, discriminação em dobro da mulher indígena (dupla jornada de trabalho), trabalho escravo em usinas de açúcar e estímulo ao uso de drogas legalizadas revelam algumas das variáveis perversas que precisam ser diagnosticadas na etapa de inserção do estudante indígena no mercado de trabalho.

Por fim, apresento duas perguntas com base em uma consideração final e provocativa: cientes de que o mercado de trabalho em terras indígenas está ficando cada vez mais restrito, repetindo, assim, o movimento historicamente identificado das crises capitalistas pelo mundo afora, seria possível prever a crise da capacidade de absorção pelo mercado de empregos disponíveis nas terras indígenas e mesmo fora delas, planejando um futuro menos comprometido para os povos indígenas, e, por outro lado, discutir em que bases morais e legais seria possível exigir o compromisso do candidato indígena com o retorno à comunidade indígena depois de formado ? $^{11}$

Uma proposição geral para orientar transversalmente um roteiro para a construção do modelo de diagnóstico, avaliação e comparação dessa política pública deveria articular o perfil biográfico escolar e profissional de cada estudante indígena em suas duas pontas - desde a inserção na educação escolar básica até a no mercado de trabalho - sem esquecer-se de detalhar, é claro, a etapa do meio, a permanência, e os dois grandes rituais de passagem que compõem essa longa trajetória: o vestibular e a formatura. Essa seria uma grande tarefa que os pesquisadores teriam pela frente no campo do ensino superior indígena e, quem sabe, no campo mais amplo da educação escolar indígena.

O modelo aqui preliminarmente proposto, que segue apresentado em forma de roteiro de variáveis, é apenas um esforço de lançar sementes num solo já devidamente fértil, mas que precisa ter diversas de suas safras urgentemente colhidas e comparadas.

\section{Referências bibliográficas}

ALBERT, Bruce. Organizações na Amazônia. [s.d.]. Disponível em: http://pib.socioambiental.org/pt/c/iniciativas-indigenas/organizacoesindigenas/na-amazonia-brasileira. Acesso em: 16 set. 2013.

\footnotetext{
11 "A poucos dias de retornar a sua região onde pretende atuar como enfermeira, Denize diz ter aproveitado intensamente a oportunidade de viver em Porto Alegre e de estudar na UFRGS. 'Levo toda esta experiência para atuar na minha comunidade', afirma." (Primeira..., 2012)
} 
AMARAL, Wagner Roberto do. As trajetórias dos estudantes indígenas nas universidades estaduais do Paraná: sujeitos e pertencimentos. 2010, 591f. Tese (Doutorado em Educação), Universidade Federal do Paraná. Curitiba, 2010.

BRASIL. Conselho Nacional de Educação. Câmara de Educação Básica. Resolução no 3, de 10 de novembro de 1999. Fixa diretrizes nacionais para o funcionamento das escolas indígenas e dá outras providências. Diário Oficial da União, Brasília, DF, 17 nov. 1999. Seção 1, p. 19. Republicada em 14 de dezembro de 1999, Seção 1, p. 58, por ter saído com incorreção no original.

BRASIL. Lei $\mathrm{n}^{\circ}$ 12.711, de 29 de agosto de 2012. Dispõe sobre o ingresso nas universidades federais e nas instituições federais de ensino técnico de nível médio e dá outras providências. Diário Oficial da União, Brasília, DF, 30 ago. 2012. Seção 1, p. 1.

CAJUEIRO, Rodrigo C. Os povos indígenas em instituições de ensino superior públicas federais e estaduais do Brasil: levantamento provisório de ações afirmativas e de licenciaturas interculturais. 2007. Disponível em: http://www.laced.mn.ufrj.br. Acesso em: 7 set. 2012.

INSTITUTO BRASILEIRO DE GEOGRAFIA E ESTATÍSTICA (IBGE). Censo 2010: população indígena é de 896,9 mil, tem 305 etnias e fala 274 idiomas. Disponível em: <http://censo2010.ibge.gov.br/noticiascenso ?view $=$ noticia\&id $=1 \&$ noticia $=2194 \& \mathrm{t}=$ censo-2010-populacaoindigena-896-9-mil-tem-305-etnias-fala-274> . Acesso em: 16 set. 2013.

GRUPIONI, Luis Donisete. Experiências e desafios na formação de professores indígenas no Brasil. Em Aberto, Brasília, v. 20, n. 76, p. 1318, fev. 2003.

POPULAÇÃO indígena no Brasil. Instituto Socioambiental. [s.d.]. Disponível em: < http://pib.socioambiental.org/pt/c/0/1/2/populacaoindigena-no-brasil >. Acesso em: 9 set. 2012.

PRIMEIRA aluna indígena da UFRGS recebe hoje diploma de graduação. Universidade Federal do Rio Grande do Sul. Porto Alegre, 31 ago. 2012. Disponível em: http://www.uffrgs.br/ufrgs/noticias/primeira-alunaindigena-da-ufrgs-recebe-hoje-diploma-de-graduação. Acesso em: 16 set. 2013.

SARZI, Fábio. Índios cobram espaço no mercado de trabalho em plenária da UGT-MS. Mundo Sindical [online], 25 mai. 2011. Disponível 
em: http://www.mundosindical.com.br/sindicalismo/noticias/noticia.

asp?id=6190\&idc[idc]. Acesso em: 16 set. 2013.

SILVA, Wilson Matos da. CINEP/ODIN, o índio e a Universidade.

Observatório de Direitos Indígenas [online], 26 jan. 2010. Disponível

em: <http://observatoriodedireitosindigenas-odin.blogspot.com>.

Acesso em: 16 set. 2013.

Luis Roberto de Paula, doutor em Antropologia Social pela Faculdade de Filosofia, Letras e Ciências Humanas da Universidade de São Paulo (USP), é professor adjunto I da Faculdade de Educação da Universidade Federal de Minas Gerais (UFMG), Belo Horizonte, MG, Brasil.

luisroberto.paula@gmail.com

Recebido em 12 de dezembro de 2012.

Aprovado em 23 de agosto de 2013. 


\section{Anexo}

Roteiro preliminar para a construção de um modelo de análise comparativa entre experiências de ensino superior indígena

\section{Etapa Acesso}

\section{Perfil da educação escolar indígena pregressa}

Perfil do estabelecimento de ensino onde o candidato cursou as etapas de escolarização

$\mathrm{Na}$ aldeia ou fora dela.

Com professor indígena ou não indígena.

Diálogos de saberes na formação.

\section{Vestibular}

Inscrição

Perfil do Edital

Formas de divulgação

Acesso a formulários

Forma de inscrição (internet, correios etc.)

Homologação da identidade indígena

Condição étnica (da etnia e do candidato)

Documentação exigida/ critérios selecionados pela instituição

Realização da prova

Local/ Meios de transporte

Conteúdo da prova (articulação entre conhecimento tradicional e não tradicional; conhecimentos disciplinares exigidos etc.)

Estatísticas:

- inscritos nos vestibulares específicos

- inscritos que realizaram a prova

- aprovados pelos vestibulares específicos

- quantidade de tentativas

\section{Perfil socioeconômico dos vestibulandos}

Renda/profissão

Gênero

Faixa etária

Estado civil/quantidade de filhos

Moradia

\section{Etapa Permanência}

\section{Infraestrutura}

Moradia (estudantil, aluguel, distância do campus, fonte de financiamento etc.)

Transporte

Alimentação (RU?)

Bolsa-auxílio 


\section{Dimensão acadêmica (Tempo "universidade"/Tempo "comunidade")}

Cursos preparatórios

Registro e acompanhamento de desempenho acadêmico:

- matriculados como estudantes indígenas nas IES (licenciatura ou vaga suplementar)

- formados na IES (licenciatura ou vaga suplementar)

Frequência e evasão

Corpo docente (perfil dos profissionais envolvidos)

Currículo (disciplinas ofertadas e cursadas)

Material Didático

Metodologias de ensino

Temáticas de TCC/Percursos

Metodologias de avaliação

\section{Dimensão da organização institucional de suporte ao projeto ${ }^{12}$}

Comissão de Acompanhamento na instituição (funcionamento, representação indígena, divulgação de informações internas sobre o projeto etc.)

Diretrizes e portarias internas para regulamentação do projeto

Organização política dos estudantes

Fontes de financiamento/recursos

Parcerias institucionais/atribuições (federal, estadual e municipal)

\section{Etapa Inserção do Mercado}

\section{Em vagas de trabalho na terra indígena (índios e não índios)}

Área de educação: docentes, diretores, técnicos, auxiliares etc.

Ensino infantil

Ensino fundamental

Ensino médio

EJA

Áreas não docentes

Saúde

Meio ambiente (agentes ambientais, assessores)

Associação indígena/projetos

Funcionário público (concursado, não concursado, federal, estadual, municipal)

\section{Em vagas de trabalho fora da terra indígena}

Funcionário público (concursado, não concursado, federal, estadual, municipal)

Trabalho informal (sem registro)

Fazendas

Comércio

Usinas

Garimpo

Madeireira

Outros

\footnotetext{
${ }^{12}$ Vejamos mais um interessante exemplo de sistematização feita por Amaral (2010, p. 317) sobre esta variável: "Institucionalização das ações de acompanhamento. Na UEL, UEM e Unioeste foi informada a existência de Comissão ou Grupo de Trabalho institucionalizado por portarias e resoluções de órgãos colegiados superiores. Na UENP não há espaço institucionalizado internamente, não havendo discussão sobre a presença dos estudantes indígenas em instâncias superiores da Instituição."
} 